\title{
Caring, men and women, nurses and doctors, and health care ethics
}

\author{
Raanan Gillon Imperial College Health Service and St Mary's Hospital Medical School, London University
}

Caring has central place in nursing and 'Gilligan's ethic of care is at the very least deserving of consideration by the next generation of nurses and those who teach them' concludes Jean Harbison in this issue of the journal (1). In her paper she pursues a contemporary theme according to which nursing, a predominantly female occupation, is properly characterised by a predominantly female moral approach. According to Professor Carol Gilligan (2), women tend to approach morality from a different but equally valid perspective from that of men - a perspective which accords moral primacy to caring within personal relationships. From this perspective, as Ms Harbison puts it a moral agent 'is characterised as one who responds to need and demonstrates a consideration of care and responsibility in relationships. In this understanding morality is seen as grounded in a perspective of caring. It is suggested that it is from this caring perspective that females view moral and ethical decision-making'; and she adds that this 'gender related theory may also be particularly appropriate for nurses, given the female domination of the profession ...' (1).

According to the empirical work of Professor Gilligan this female perspective on morality contrasts with that of males, for whom respect for autonomy and a concomitant pursuit of achievement - and justice tend to be the predominant moral concerns. Historically it has been the male perception of morality that has been dominant, she argues, but unjustifiably so, for the female perspective on morality is just as valid as the male.

It is surely not only nurses but also doctors and indeed all health care workers (indeed all people!) for whom recognition of the importance of caring - for others and also for self - and of the importance of personal relationships and commitments within them is 'appropriate'. In the context of health care, a morality which gave excessive weight to detachment and impartiality, respect for autonomy and an ethic of achievement would present major impediments to the development of properly caring relationships, as Ms Harbison points out, and as would surely be acknowledged by all reflective health care workers. So too would her important point about the importance of assessing individual cases in their context and their particularity.
Nonetheless it is important to note some potential sources of misinterpretation of both Ms Harbison' ${ }^{\circ}$

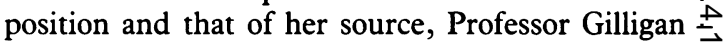
misinterpretations that are already to be heard in inadequately reflective discourse on alleged morab incompatibilities between male and female ethics ${ }_{2}$ between nursing and medical ethics, and between different approaches to health care ethics morg generally.

The first misinterpretation is that women have different sort of ethics from men, and that the two sorts of ethics are simply incompatible. On an outsider's assumption that Professor Gilligan's empirical wor is sound, women tend to develop their moral judgemets from a perspective of 'attachment' to, and responsibility for, other people. Describing her worf with young adult women Professor Gilligan sayso 'morality is seen by these women as arising from the experience of connection and conceived as a problem of inclusion rather than one of balancing claims. The underlying assumption that morality stems from attachment is explicitly stated ... [by one of he subjects]' (3).

Conversely for the young men in her studie '[i]nstead of attachment, individual achievement rivet's the male imagination' (4). Professor Gilliga䊎. hypothesises that for young men their development as individuals, their development of a sense of their ow identity, involves separation from others, and in so fao as others are involved, that involvement is tied to qualification of identity rather than to its realisation... Power and separation secure the man in an identit achieved through work, but they leave him at $\mathbb{Q}$ distance from others, who seem in some sense out of his sight'. Hope however is at hand for the young man, ał 'intimacy becomes the critical experience that bringe the self back into connection with others, making if possible to see both sides - to discover the effects of actions on others as well as their cost to the self. The experience of relationship brings an end to isolation which otherwise hardens into indifference, an absence्ड of active concern for others, though perhaps $\vec{\Phi}$ willingness to respect their rights ... the knowledg $\overparen{\oplus}$ gained through intimacy changes the ideologicat morality of adolescence into the adult ethic of taking care' (5). 
In the case of the development of women, however, they 'define their identity through relationships of intimacy and care' - and judge it 'by a standard of responsibility and care' (3). In women's development, according to Professor Gilligan, there is a 'fusion of identity and intimacy' which leads to a standard of moral judgement which 'is a standard of relationship, an ethic of nurturance, responsibility and care' whose strength is measured in the 'activity of attachment ("giving to", "helping out", "being kind", "not hurting")' (6). But though this standard is initially perceived as a sort of absolute, as the women develop this 'absolute of care, defined initially as not hurting others, becomes complicated through a recognition of the need for personal integrity. This recognition gives rise to the claim for equality embodied in the concept of rights, which changes the understanding of relationships and transforms the definition of care' (7).

The point to be stressed here is that Professor Gilligan is describing a developmental process that differs between men and women, involving a fundamental difference in their starting perspective on morality. But as she points out in her last chapter, as men and women mature, they increasingly come to appreciate the importance of both perspectives. 'Thus starting from very different points, from the ideologies of justice and care, the men and women in the study come, in the course of becoming adult, to a greater understanding of both points of view and thus to a greater convergence in judgement' (8). Thus it is a mistake, and a potentially very destructive mistake, to interpret In a Different Voice as arguing that men and women have different sorts of morality and that these different moralities are incompatible. Rather, her claim is that in their development towards a mature morality men and women tend to start with very different perspectives, men tending to see justice, rights and autonomy as the only important moral issues, women tending to see caring, not harming, and responsibility for others as the only important moral issues. As they develop a more mature, less absolutist, moral understanding they come to understand the importance of all these potentially conflicting features for the complexities of a mature morality.

The second misinterpretation too can be avoided, once it is recognised that Professor Gilligan's thesis is not that men and women have different and incompatible moralities but rather that men in their moral development tend to give too absolute a priority to justice rights and respect for autonomy while women in their moral development tend to give too absolute a priority to caring for, nurturing, benefiting and avoiding harm to others, and that all these potentially conflicting features are important to a mature common morality. According to this second misinterpretation, nursing ethics are simply different from medical ethics and the two are mutually incompatible.

Again Professor Gilligan's empirical findings may well be an important reminder that nurses, many of whom are young women, will tend to view morality from the 'female' perspective of attachment, caring and nurturing; and that young male doctors and medical students may tend to view it from the 'male' perspective of detachment, rights, autonomy and justice. But this is not to show that nurses and doctors have different and incompatible moralities. To start with, some half of the younger doctors, in Britain at least, are women, and so presumably they too will tend towards the 'female' moral perspective of care. Secondly mature medical morality has since Hippocratic times incorporated at its centre a moral concern for nurturing and care for its sick patients; meeting the needs of sick patients has been the moral driving force of medical ethics since its inception. Thirdly it would be mistaken to believe that either medical or nursing ethics could adequately rest entirely on an ethic of care; the 'male' moral concerns of justice rights and respect for autonomy are as important in a mature nursing ethics as they are in a mature medical ethics. Thus it would be simply mistaken to believe that medical ethics is 'male ethics' and that nursing ethics is 'female ethics', or to interpret Professor Gilligan's work as supporting this mistaken belief.

The third potential misinterpretation of Professor Gilligan's work is to see it as demonstrating a fundamental incompatibility between different ways of approaching health care ethics - especially between those approaches that would ally themselves to Kantian ethics, emphasising respect for autonomy, duties, justice; those that would ally themselves to consequentialist approaches to ethics and their central moral concern with the harm and benefit that actions and inactions produce; those that would ally themselves with Aristotelian virtue ethics, in which the central moral concern is with 'the good person'; and those that would ally themselves with contemporary 'rights-based ethics' in which respect for people's rights (as distinct from mere attention to people's duties) is seen as the central moral concern. While it might be justifiable to infer from Professor Gilligan's work that during their moral development men and women might tend to identify themselves differently with some of these approaches, there is nothing in her work to suggest fundamental incompatibilities between any of them.

Rather, it may be that these approaches too are simply 'different voices', all needing to be heard, understood and combined into an adequately complex and mature health care ethics.

\section{References}

(1) Harbison J. Gilligan: a voice for nursing? fournal of medical ethics, 1992; 18: 202-205.

(2) Gilligan C. In a different voice. Cambridge, Mass and London: Harvard University Press, 1982.

(3) See reference (2): 160 .

(4) See reference (2): 163.

(5) See reference (2): 163-164.

(6) See reference (2): 159.

(7) See reference (2): 166.

(8) See reference (2): 167. 